\title{
RELAÇÃO ENTRE IFRS MANDATÓRIO E CRIAÇÃO DE VALOR
}

\author{
Johnny Silva Mendes 1 \\ Olivan da Silva Rabêlo 2 \\ Wilson Toshiro Nakamura 3 \\ Joelson Oliveira Sampaio ${ }^{4}$
}

- Artigo recebido em: 30/05/2018 -" Artigo aceito em: 13/01/2020 -" Segunda versão aceita em: 14/02/2020

\section{RESUMO}

Com o intuito de alcançar a convergência contábil, melhorar a comparabilidade e mensuração do valor econômico da firma, as normas IFRS - Internacional Financial Reporting Standards (Normas Internacionais de Informações Financeiras, em português), estabelecidas de forma mandatória no Brasil no ano de 2010, refletem menor custo de capital e consequente criação de valor para as firmas. O objetivo principal da pesquisa foi investigar empiricamente a relação entre IFRS mandatório e criação de valor das empresas de capital aberto não financeiras brasileiras. Foi utilizada uma amostra de empresas brasileiras regularmente negociadas na B3 (Brasil, Bolsa e Balcão) entre 2003 e 2014. O método econométrico utilizado foi diff-in-diff, que isola o efeito do IFRS por meio das características não observadas. Estimaram-se modelos com dados agrupados e painel com efeito aleatório. Para as métricas de criação de valor, foram encontrados efeitos positivos e significantes nas variáveis $Q$ de Tobin e Market-toBook. Os dados evidenciam que o IFRS mandatório impacta positivamente a criação de valor e mostram o aumento da qualidade nos demonstrativos financeiros.

Palavras-Chave: IFRS. Criação de Valor. Diferença em Diferenças.

1 Doutorando em Finanças pelo PPG em Administração da Universidade Presbiteriana Mackenzie. Professor da Graduação de Economia e Administração da Fundação Armando Álvares Penteado (FAAP). Endereço: R. Alagoas, 903 - Higienópolis, São Paulo - SP, 01242-902. Telefone: (1 1 ) 3662-7056. E-mail: johnnyssmm@gmail.com.

https://orcid.org/0000-0001-8007-2693.

2 Doutor em Economia pelo Programa de Pós-Graduação em Economia da Universidade Federal de Pernambuco (PIMES-UFPE). Professor da Graduação e Pós-Graduação da Faculdade de Administração e Ciências Contábeis (FACC) da Universidade Federal de Mato Grosso (UFMT). Endereço: Av. Fernando Corrêa da Costa, n 2367 - Bairro Boa Esperança. Cuiabá - MT - 78.060-900. Telefone: (65) 3313-7343. E-mail: olivanrabelo@ufmt.br.

https://orcid.org/0000-0002-4940-8440.

3 Doutor em Administração pela FEA/USP. Professor do PPG em Administração da Universidade Presbiteriana Mackenzie. Endereço: R. da Consolação, 896 - Higienópolis, São Paulo - SP, 01302-907. Telefone: (11) 21 14-8000. E-mail: wtnakamura@vol.com.br.

https://orcid.org/0000-0002-4697-5685.

4 Doutor em Teoria Econômica pela Faculdade de Economia, Administração e Contabilidade - USP. Doutor em Finanças Corporativas e Mercados Financeiros pela Fundação Getúlio Vargas. Endereço: Av. 9 de julho, 2029 Edifício John F. Kennedy - Bela Vista, São Paulo - SP, 01313-902. Telefone: (11) 3799-3350. E-mail: joelsonssp@gmail.com.

https://orcid.org/0000-0002-4697-5685. 


\title{
RELATIONSHIP BETWEEN IFRS MANDATORY AND VALUE CREATION
}

\begin{abstract}
In order to achieve accounting convergence, improve the comparability and measurement of the firm's economic value, the International Financial Reporting Standards (IFRS), mandatorily established in Brazil in 2010, reflect lower cost of capital and consequent creation of value for the firms. The main objective of the research was to empirically investigate the relationship between Mandatory IFRS and value creation of Brazilian non-financial public companies. A sample of Brazilian companies regularly traded on B3 (Brasil, Bolsa e Balcão) between 2003 and 2014 was used. The econometric method used was diffs-in-diffs, which isolates the effect of IFRS through unobserved characteristics. Models with pooled data and panel with random effect were estimated. For value creation metrics, positive and significant effects were found on Tobin's q and Market-to-Book variables. The data show that the mandatory IFRS positively impacts the creation of value and that there is an increase in quality in the financial statements.
\end{abstract}

Keywords: IFRS. Value creation. Diff-in-diff.

\section{INTRODUÇÃO}

A teoria econômica sugere que as empresas tenham o compromisso com a criação de valor para o acionista (Seth, 1990). Ao longo do tempo, as empresas podem se comprometer a pagar dividendos e aumentar os ganhos de capitais, cumprindo a meta com a criação de valor (Megna \& Klock, 1993). Há vários fatores que interferem na criação de valor, que afetam tanto os ativos tangíveis quanto os intangíveis (Kayo, Kimura, Martin, \& Nakamura, 2006; Teh, Kayo, \& Kimura, 2008). Bushman e Smith (2001, 2003) listam alguns: quantidade de divulgação de informações de qualidade para o mercado; assimetria de informação; risco da empresa; custo de capital e liquidez da empresa. Dentre esses fatores, a premissa maior, que será explorada amplamente neste artigo, está relacionada com a melhor qualidade das informações contábeis e as normas contábeis adotadas, e isso está em linha com demandas de pesquisas sugeridas por importantes autores que se dedicam a essa área de pesquisa (Barth, Landsman, \& Lang, 2008).

Duas características contribuem essencialmente para que haja maior divulgação de informações de qualidade para o mercado: (I) as normas contábeis que são capazes de refletir efeitos combinados e positivos nos relatórios contábeis, incluindo padrões, aplicação e litígios (Barth et al., 2008; Bushman \& Smith, 2001, 2003); (II) o ambiente institucional em que as normas contábeis estão amparadas. Essa última é bastante plausível, uma vez que, em mercados globalizados, o investidor pode subavaliar o ambiente institucional de acordo com o grau de enforcement do país (Houqe \& Easton, 2013; La Porta, Silanes, Shleifer, \& Vishny, 1998; Soderstrom \& Sun, 2007).

Com o objetivo de atender ao público externo, a contabilidade é estruturada na base de divulgação com premissa de conservadorismo, ou seja, tem-se por objetivo atender a padrões de mensuração e verificabilidade, e há, com isso, a intenção de refletir os valores econômicos das firmas (Soderstrom \& 
Sun, 2007). O conservadorismo recebe uma forte crítica por não representar, ao longo do tempo, um dos importantes objetivos econômicos: mensurar o valor real da firma (Verrecchia, 2001). Com isso, o mercado pode não valorizar de forma suficiente as informações que recebe, e os investidores - que estão entre os usuários da informação contábil - consequentemente tendem a subavaliar as empresas, o que pode levar à destruição de valor (Kayo et al., 2006; Teh et al., 2008; Verrecchia, 2001).

Nesse sentido, os demonstrativos contábeis que não fornecem informações de qualidade provocam, em vez de criação, destruição de valor (Bushmamn \& Smith, 2001, 2003; Lima, 2009). Para Teh et al. (2008), a qualidade das informações contábeis tem relação positiva com o valor da firma; por outro lado, quanto menor a qualidade das informações, maior a assimetria informacional. Reforçam, portanto, esse contexto negativo da qualidade informacional e estão alinhados com o artigo de Castro Junior, Conceição e Santos (2011), que diz que a assimetria informacional tem impacto direto, aumentando o custo de capital das empresas, o que, por consequência, atinge negativamente a criação de valor das companhias.

O Internacional Financial Reporting Standards (IFRS) equivale ao padrão internacional para divulgação dos relatórios contábeis. Esse padrão tem sido adotado em vários países, e a Lei n 11.638/07, promulgada em dezembro de 2007, estabeleceu que o Brasil adotasse também tal norma obrigatoriamente, a partir do ano fiscal de 2010. Sendo assim, nos anos fiscais de 2008 e 2009, as empresas passaram por um período de adaptação, isto é, não obrigatoriedade de publicação de seus relatórios no padrão IFRS.

A literatura acadêmica (Daske, Hail, Leuz, \& Verdi, 2008), corroborada por órgãos reguladores (Catty, 2013) e de referência sobre o tema, como também pela sociedade em geral, tem apresentado evidências de que a adoção mandatória do IFRS potencialmente influencia positivamente a criação de valor das firmas. Isso está evidenciado nas pesquisas de Pae, Thornton e Welker (2006), que encontraram relação positiva entre qualidade da informação e criação de valor após a adoção do IFRS mandatório na União Europeia (UE). Diante dessa oportunidade no Brasil, onde o período mandatório teve início em 2010, este estudo procurou responder ao seguinte problema de pesquisa: qual a relação existente entre a adoção do IFRS mandatório e a criação de valor em empresas brasileiras listadas na B3 de 2003 a 2014 ?

Considerando a questão de pesquisa, este artigo tem por objetivo, portanto, verificar a relação existente entre a adoção mandatória do IFRS e criação de valor em empresas listadas na B3, no período de 2003 a 2014.

Entende-se por criação de valor o conceito de Kayo et al. (2006), que ocorreria quando o valor econômico da empresa é aumentado, sendo possível mensurá-lo pela somatória dos ativos tangíveis e intangíveis. Ainda, conforme Copeland, Koller e Murrin (2002), cria-se valor quando a empresa obtém retorno do investimento superior ao custo de oportunidade, e, para que isso ocorra, devese escolher estratégias que maximizem o valor presente dos fluxos de caixa futuros; tal conceito está em linha com a pesquisa de Coombs e Bierly (2006).

Alguns estudos já testaram a relação das normas IFRS no Brasil. No entanto, diferentemente de Silva (2013), Carvalho (2014) e Gasparini (2015), que testaram o custo implícito de capital, este estudo procurou inovar, testando a criação de 
valor que incorporar informações contábeis aos valores de caixa futuros trazidos a valor presente. Essa oportunidade trouxe maior clareza sobre os benefícios de uma norma baseada em princípios e está em consonância com as sugestões de novas pesquisas em Ferreira, Flores e Martins (2015).

Seguindo duas sugestões de lacunas encontraras em Houqe e Easton (2013), este artigo também se justifica porque: (I) testou uma amostra sem o efeito da contaminação do período voluntário de adoção das normas IFRS de 2008 e 2009, e (II) foi investigado se o IFRS mandatório apresentou relação positiva e significante com criação de valor em países de baixo enforcement, que apresentam a modalidade civil law de direito.

A última justificativa também decorre do fato de que se tratou de um evento exógeno, visto que a lei 11.638/07 foi promulgada em 28 de dezembro de 2007. Conforme destacaram Ferreira et al. (2015), o mercado não esperava receber essa notícia praticamente no último dia do ano. Isso, então, possibilitou que se verificasse a relação do IFRS mandatório e a criação de valor por meio do método diff-in-diff ou "diferença em diferenças", uma vez que se trata de um "experimento natural (ou quase um experimento)". Portanto, houve uma oportunidade de capturar, de forma mais apropriada e com método econométrico mais adequado, segundo a teoria, as mudanças ocorridas nos relatórios contábeis para melhor harmonização das normas. Verificou-se, por isso, se a adoção do IFRS mandatório teria associação positiva e significativa na criação de valor das firmas, conforme apontado em Li (2010). O uso do método representa uma evolução na análise realizada até o momento, tanto na literatura nacional como internacional (Li, 2010). Além disso, todas as inovações realizadas no trabalho, em termos de variáveis explicativas e universo amostral, configuramse como importantes contribuições (Ball, 2006): primeiro, em relação à literatura internacional, pelo uso dos estimadores de dados em painel, que criam a possibilidade de contornar as variáveis não observáveis e constantes ao longo do tempo, reduzindo o seu viés; e, segundo, pelo teste de robustez utilizado, confirmando o modelo alternativo do trabalho, bem como a sua hipótese (Wooldridge, 2010).

Além desta introdução, o artigo traz uma segunda sessão, que corresponde à revisão da literatura; a terceira sessão discute os métodos; na quarta sessão, estão resultados alcançados; e, na quinta sessão, as conclusões.

\section{REVISÃO DA LITERATURA}

\subsection{IFRS}

O objetivo de alcançar a internacionalização das regras de demonstrações financeiras, para se ter demonstrações fidedignas, comparáveis, capazes de mitigar a assimetria de informação (Soderstrom \& Sun, 2007) que prejudica a avaliação das empresas no mercado de capitais, teve início antes mesmo da criação do International Accounting Standards Committee (IASC) precursor do International Accounting Standards Board (IASB) - em 1973 (Catty, 2013).

No Brasil, foram a Lei 11.638/07 e a medida provisória $n^{\circ}$ 449/08 que atribuíram à CVM a responsabilidade para criar o processo de mudança das 
normas contábeis financeiras e garantir a conformidade do padrão internacional do IFRS no país (Gasparini, 2015; Catty, 2013).

A adoção do IFRS no Brasil ocorreu especificamente em dois períodos, sendo 2008 e 2009 o primeiro - momento em que as empresas adotaram voluntariamente o IFRS -, e o segundo, a partir de 2010, quando se deu a obrigatoriedade para todas as empresas de capital aberto (Gasparini, 2015).

Tais mudanças nos moldes de divulgação das informações contábeis para os padrões internacionais têm o objetivo de atender o mercado, cada vez mais competitivo, com informações tempestivas e confiáveis, com o intuito de auxiliar na tomada de decisão das diversas organizações, já que mitigam a assimetria de informação, que atinge 0 valor econômico das firmas negativamente e diminui a liquidez (Rezende, Almeida, \& Lemes, 2015; Bushman \& Smith, 2001, 2003). Entretanto, persiste o debate que questiona se a adoção do IFRS traz melhoria para a qualidade das informações (Rezende et al., 2015).

Para Barth et al. (2008), que pesquisaram a qualidade das informações contábeis nas empresas que adotaram as normas Internacional Accounting Standard (IAS) em 21 países, entre 1994 e 2003, a adoção das normas IAS refletiu efeitos positivos, com maior qualidade contábil. Isso inclui melhor padronização, interpretação, mensuração e fidedignidade dos relatórios financeiros. Essas empresas que adotaram as normas IAS, dizem os autores, apresentaram menores gerenciamentos de resultados e maior associação dos valores contábeis com os retornos das ações.

Soderstrom e Sun (2008) investigaram se as mudanças nos sistemas contábeis para as normas IFRS na União Europeia (UE) no ano de 2005 apresentaram grande impacto no ambiente das empresas desses países. Os autores argumentam que as diferenças contábeis das empresas têm relação com os sistemas legais, políticos e jurídicos de cada país. Além disso, a qualidade dos relatórios financeiros é, portanto, um resultado de equilíbrio entre custo e benefício: custo de divulgação, que inclui o custo de preparar relatórios financeiros e divulgar informações; e o benefício de atender à demanda de informações das contrapartes interessadas, governos e mercado. Com isso, concluíram que a qualidade contábil, após a adoção do IFRS, depende de três fatores: (I) a qualidade dos padrões; (II) sistema jurídico e político de um país; e (III) incentivos para relatórios financeiros.

A Alemanha é considerada um dos países da UE que possuem maior enforcement (LA PORTA et al., 1998). Por isso, alguns autores têm estudado se as normas contábeis internacionais apresentam relação positiva e significante com a qualidade das informações contábeis. Por exemplo, Bartov, Goldberg e Kim (2005), que estudaram a relação entre a qualidade das informações contábeis e as normas German GAAP, US GAAP e IAS em empresas alemãs; eles perceberam que os relatórios internacionais, ou seja, US GAAP e IAS, fornecem maior qualidade nas informações contábeis em relação aos padrões alemães (German GAAP). Ainda indicaram que as normas internacionais de contabilidade terão maior adesão de fidedignidade em países que possuam maior enforcement.

O estudo de Armstrong, Barth, Jagolinzer e Riedl (2010) investigou as reações do mercado de ações em 16 eventos relacionados à adoção do IFRS entre os anos de 2003 e 2005 em países da UE. A pesquisa foi capaz de identificar três grupos de países que apresentaram relação significativa estatisticamente,

62 Revista Contabilidade Vista \& Revista, ISSN 0103-734X, Universidade Federal de Minas Gerais, Belo Horizonte, v. 31, n. 1, p. 58-84, jan./abr. 2020 
antes e após o IFRS na UE: primeiro, encontraram relação positiva para países que apresentavam menor qualidade nas informações contábeis durante o período anterior à adoção do IFRS; segundo, identificaram também relação negativa quando a adoção ocorreu em países de baixo enforcement; e, por último, diagnosticaram relação positiva para países que apresentavam alta qualidade de informações contábeis antes do período de adoção do IFRS.

Houqe e Easton (2013) investigaram o efeito da adoção do IFRS obrigatório sobre a qualidade das informações nos relatórios financeiros em países de baixa proteção aos investidores para empresas não financeiras. Foi examinado o efeito da adoção do IFRS obrigatório na França, Suíça e Suécia, três países da Europa ocidental que adotam o direito civil com origem no French-CivilLaw, caracterizado por ter baixa proteção aos investidores pelo fórum Econômico Mundial 2011/2012, "Relatório de Competitividade Global" e suas respectivas tradições jurídicas de direito civil. Ao utilizar a análise de dados entre 2003 e 2011, foi encontrada uma melhora significativa, tanto na precisão das previsões dos analistas quanto na menor dispersão dessas previsões após a adoção obrigatória do IFRS nos três países. Esses resultados sugerem que a adoção obrigatória do IFRS em países de baixa proteção aos investidores melhora a qualidade da informação.

\subsection{Criação de Valor}

A criação de valor ocorre quando as empresas aumentam o valor econômico. Segundo Kayo et al. (2006), isso é possível pela soma dos ativos tangíveis e intangíveis e, em conformidade a esse conceito, Copeland et al. (2002) atribuem criação de valor somente quando o valor investido é superior ao custo de oportunidade, ou seja, quando o valor presente dos fluxos de caixa for superior ao custo de capital da empresa.

Os ativos intangíveis não possuem corpo físico. Na maioria das vezes, são desmembramentos dos ativos físicos, que geram benefícios econômicos futuros em favor da empresa (CPC, 2010; Kayo et al., 2006), tais como marca, patentes ou um setor organizacional singular (Teh et al., 2008). Portanto, o ativo intangível pode ser capturado pelo setor de atuação da empresa (Megna \& Klock, 1993). Essa informação faz sentido, uma vez que alguns setores se destacam em pesquisa e desenvolvimento (P\&D) por criarem, por exemplo: novas formas de extração de petróleo, podendo ser em alto-mar e em águas profundas; softwares de produção, de controle financeiro ou de contabilidade específicos para o negócio, que ajudam a aumentar a rentabilidade e o crescimento dos benefícios futuros ou se apropriam de tecnologias que os habilitam a novos mercados antes não explorados, como streaming (forma de transmissão de som e imagem sem a necessidade de efetuar download); entre outras formas de intangíveis.

Os ativos tangíveis se referem aos ativos físicos e capital de giro. Para Kayo et al. (2006), é difícil desvincular os ativos tangíveis dos intangíveis, porém a combinação desses descreve o valor econômico real da empresa, que está, inclusive, associado a benefícios econômicos futuros. Logo, apesar da importância crescente dos intangíveis, os ativos tangíveis continuam em evidência e são de grande importância para mensuração da criação de valor (Perez \& Famá, 2015). 
Sendo assim, fica evidente que as empresas estarão criando valor para os acionistas, somente se obtiverem criação de valor. Para tanto, a empresa deverá fazer tal mensuração por meio da somatória dos ativos tangíveis e intangíveis (Kayo et al., 2006) registrados adequadamente nos seus demonstrativos financeiros.

Como dito em Armstrong et al. (2010), se os analistas e o mercado em geral se utilizam em grande parte das informações disponíveis no mercado, como fatos relevantes ou demonstrativos contábeis para avaliarem as empresas, isso significa que a menor harmonização das normas na mensuração e na divulgação destas informações contábeis de forma fidedigna pode prejudicar a comparabilidade de ativos (Soderstrom \& Sun, 2007), o que pode destruir valor das empresas, dependendo das informações que o mercado captura nos relatórios (Pae et al., 2006).

Ocorre que as empresas podem estar sendo avaliadas abaixo do seu valor econômico, sendo prejudicadas pela assimetria de informação (Soderstrom \& Sun, 2007). Problemas como a assimetria de informação ocorrem quando uma das partes envolvidas não detém todas as informações; por exemplo, gestores e analistas de mercado podem aumentar seu custo de aprendizagem quando as normas não apresentarem alto poder de comparabilidade e mensuração dos ativos (Leland \& Pyle, 1977).

Portanto, pode-se notar que os autores discutidos até aqui relacionaram o aumento do disclosure e mitigação da assimetria informacional com a alta qualidade das informações nos demonstrativos financeiros aplicados à tomada de decisão para criação de valor das empresas.

Por isso, há o aumento da demanda por alta qualidade das informações, visto que se tem o objetivo de atender a uma demanda global. $E$, desde a década de 70, o mercado vêm se organizando nesse sentido, com o intuito de alinhar uma estratégia que possa atender adequadamente a essas normas de qualidade das informações contábeis. Vem-se evoluindo ao que se conhece atualmente como International Financial Reporting Standards (ou, simplesmente, IFRS).

\subsection{Relação entre IFRS e Criação de Valor}

O IFRS, diferentemente da metodologia BR GAAP, apresentou conceitos baseados em princípios que, em tese, capacitam as empresas a mensurar e registrar com maior conformidade as informações acerca de seu valor econômico real (Catty, 2013; Gu \& Li, 2007; Soderstrom \& Sun, 2007). Com isso, espera-se maior fidedignidade nos demonstrativos financeiros, buscando, desta forma, mitigar a assimetria de informação, que pode ser refletida na menor percepção dos riscos, relacionados tanto a ativos tangíveis quanto intangíveis.

Pae et al. (2006), que compararam Q de Tobin antes e após a adoção do IFRS na União Europeia, encontraram relação positiva e significante para criação de valor. Para Silva (2013), o benefício do IFRS foi melhorar a mensuração tanto dos intangíveis quanto dos tangíveis: pagamento baseado em ações, teste de impairment, registro de propriedade para investimento, registro da depreciação de acordo com o padrão de consumo dos benefícios do ativo, registro de propriedades para investimento, entre outros. 
Ferreira et al. (2015) também apresentam algumas rubricas que foram atingidas pelas novas normas contábeis. São elas: ativos biológicos, instrumentos financeiros, mensuração do valor justo, entre outras. Para os autores, as normas IFRS trouxeram elevação da primazia econômica sob forma jurídica, além da inserção da mensuração de alguns ativos e passivos a valor justo. Sendo assim, as normas IFRS elevam as responsabilidades das empresas na escolha contábil; elas buscam expressar sua real posição econômica (Ferreira et al., 2015).

Fica evidente que tanto Pae et al. (2006) quanto Silva (2013) e Ferreira et al. (2015) estão de forma, pelo menos indireta, referindo-se ao tema da criação de valor. Claro que o objetivo do IFRS não é necessariamente aumentar o valor das empresas, e sim mensurá-lo e registrá-lo adequadamente. Para Soderstrom e Sun (2007), há, pelo menos de forma indireta, a percepção de que as mudanças na qualidade das informações dos demonstrativos são incorporadas aos preços das ações. Logo, dependendo das empresas e do setor de atuação, pode-se revelar tanto a destruição de valor quanto a criação. Assim, o mais importante é que o IFRS revela o real valor econômico das empresas (Gasparini, 2015; GU \& Li, 2007; Silva, 2013).

Percebe-se, então, que a qualidade das informações contábeis interfere diretamente na criação de valor das empresas, ora impactando na criação de valor, ora podendo gerar destruição de valor (Pae et al., 2006).

De acordo com o raciocínio desenvolvido até este ponto, evidenciou-se que quanto maior a qualidade das informações contábeis, maior será o poder de comparabilidade. E, diante desse cenário, os custos de acesso às informações tendem a diminuir, melhorando os processos e diminuindo também os custo de aprendizagem dos usuários das informações (Soderstrom \& Sun, 2007). Nesse sentido, o aumento da qualidade das informações contábeis pelas normas internacionais, IFRS, podem se refletir nos preços das ações, que diretamente impactam a criação de valor das empresas (Bushman \& Smith, 2001, 2003). Diante disso, este artigo pretende testar a seguinte hipótese de pesquisa (H1): A adoção mandatória do IFRS impacta positivamente na criação de valor das empresas.

\section{METODOLOGIA}

Na busca por responder o problema pesquisado, faz-se necessário realizar um estudo empírico-analítico, pois, segundo Martins (2000), essa abordagem utilizou técnicas de coleta, tratamento e análise de dados quantitativos, além de ter forte preocupação com a relação entre as variáveis pesquisadas. Por isso, esta pesquisa foi do tipo descritiva: segundo Hair, Babin, Money e Samovel (2005), trata-se de verificar as características descritivas entre variáveis. Posto isso, o presente artigo utilizou o método quantitativo, descritivo, baseado em procedimentos estatísticos, a partir do software Gret ${ }^{\circledR}$.

Procurou-se avaliar se houve criação de valor resultante da adoção do IFRS mandatório nas empresas brasileiras. A relação entre as variáveis dependentes de criação de valor pôde ser capturada por meio da aplicação de regressão. A relação existente entre as variáveis dependentes e explicativas foi melhor estudada a partir da análise de regressão linear múltipla com dados organizados em painel, pois permitiu acompanhar as mesmas empresas ao longo do tempo (Wooldridge, 2010). Ainda segundo o mesmo autor, os dados em painel 
são muito apropriados para analisar o efeito das políticas públicas, em razão de ser possível observar o comportamento das empresas em diferentes momentos ao longo do tempo.

Ressalta-se que este estudo não se propôs a identificar resultados marginais da relação do IFRS mandatório com a criação de valor, mas verificar os efeitos advindos da adoção obrigatória das normas IFRS.

A análise da criação de valor, antes e depois do IFRS mandatório, se deu pelo estimador diff-in-diff (diferença em diferenças). Este modelo com estimador diff-in-diff já foi adotado em trabalhos como o de Li (2010), de Balakrishnan, Li e Yang (2012), Silva (2013), Carvalho (2014) e Gasparini (2015). Tal modelo procurou analisar experimentos naturais (ou quase-experimento) que são considerados exógenos por uma mudança imposta na política ou do ambiente em que o evento está inserido (Wooldridge, 2010). Um quase-experimento caracteriza-se como um evento não natural, que não foi controlado em um laboratório; este costuma ocorrer após um evento exógeno, não previsível, como, por exemplo, leis e políticas públicas. Para este artigo, o evento do IFRS foi divulgado como lei em 28 de dezembro de 2007 com início efetivo em Janeiro de 2008; por isso, foi considerado aqui como exógeno, assim como nos artigos que mesuraram o impacto da adoção do IFRS: por exemplo, Li (2010), Balakrishnan et al. (2012), Silva (2013), Carvalho (2014) e Gasparini (2015).

Assim como no trabalho de Carvalho (2014), o artigo foi norteado pela investigação do modelo com estimador diff-in-diff. Este modelo apresentou dois grupos: um de tratamento e outro de controle. As empresas do grupo de tratamento representaram aquelas que sofreram impactos econômicos apenas após a adoção do IFRS mandatório, enquanto o grupo de controle representou aquelas empresas que não sofreram o impacto econômico do evento exógeno. Similarmente ao trabalho de Carvalho (2014), neste artigo, o grupo de controle foram as empresas que aderiram voluntariamente aos padrões internacionais de contabilidade (US GAAP) e, por conta disso, sofreram impacto em proporção diferente quando comparadas às empresas que somente adotaram o IFRS no período mandatório.

Carvalho (2014) diz que, pelo fato de já terem adotado de forma voluntária O US GAAP, as empresas já obtiveram os mesmos benefícios econômicos que o IFRS mandatório proporciona e, com isso, o grupo de empresas que aderiram ao US GAAP não sofreram impacto antes e após ao IFRS mandatório (ou pelo menos capturaram menor impacto) e, de forma adaptativa, se habilitam a fazer parte do grupo de controle. A fim de que se possa analisar a relação através do diff-in-diff, procurou-se demarcar, por meio da Figura 1, os efeitos esperados sofridos entre 0 grupo de tratadas e controladas. Esta afirmação em torno dos efeitos econômicos entre US GAAP e IFRS já foi testada antes na pesquisa de Daske (2006).

Daske (2006), em sua pesquisa, não encontrou diferenças significantes nos benefícios econômicos gerados entre as normas internacionais de contabilidade (IAS) e as normas adotadas nos Estados Unidos (US GAAP). Logo, são padrões equivalentes, ambas carregam o mesmo nível de qualidade normativa (ver Figura 1). Conforme Daske (2006), as empresas que adotam IFRS ou US GAAP não apresentam diferenças significativas no impacto econômico. Sendo assim, pôdese pressupor que empresas que adotaram voluntariamente o US GAAP antes do 
período mandatório do IFRS já haviam incorporado os mesmos benefícios econômicos de melhor harmonização do padrão de contabilidade que as empresas que adotaram o IFRS somente no período obrigatório (Armstrong et al., 2010; Pae et al., 2006).

Para analisar um experimento natural, como já mencionado, dois grupos de empresas são necessários: o grupo de controle (este não afetado pela mudança) e um outro grupo, de tratamento, afetado pelo evento exógeno, sendo que o método com estimador de diferença em diferenças controla as características não observáveis ao longo do tempo e, com isso, isola o efeito da política no grupo Tratado (Wooldridge, 2010).

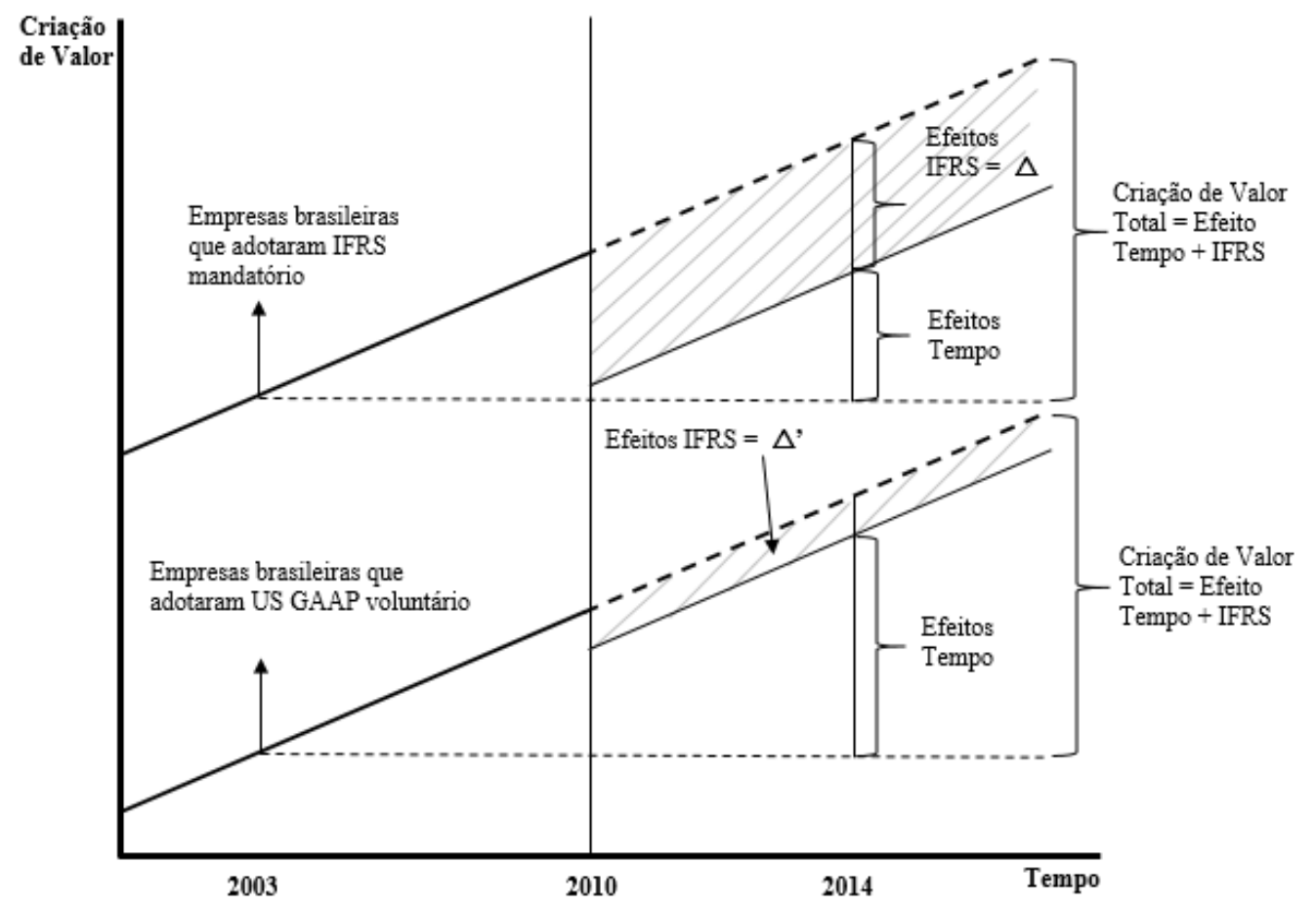

Figura 1 - Criação De Valor e Adoção do IFRS Mandatório

Fonte: Adaptado de Carvalho (2014, p. 87).

Nota: A reta da parte superior indica as empresas do grupo de tratadas que sofreram variação na criação de valor $(\triangle)$ pelas normas IFRS e pelo tempo (variáveis não observáveis). A reta da parte inferior do gráfico representa o grupo de controle e, teoricamente, sofre apenas o efeito do tempo ou o efeito das variáveis não observáveis, conforme apresentado nos trabalhos de Carvalho (2014) e Daske (2006). Considerando a hipótese de pesquisa sobre a relação entre criação de valor e adoção do IFRS mandatório, é esperada relação positiva e significante, ou seja, $\Delta^{\prime}<\Delta \mathbf{e} \Delta>\mathbf{0}$. A variação $\Delta^{\prime}$ equivale a um pequeno efeito do IFRS mandatório nas empresas do grupo de controladas que adotaram o US GAAP antes do período mandatório.

Para tanto, é necessário que sejam coletados dados antes e depois do evento exógeno, nos dois grupos analisados. A amostra então será composta por quatro grupos: Grupo de controle antes do IFRS, Grupo de Controle depois do IFRS, Grupo de Tratamento antes do IFRS e Grupo de Tratamento depois do IFRS. Para melhor mensuração do resultado, não será considerado o período voluntário 
do IFRS dos anos de 2008 e 2009, visto que o objetivo deste trabalho é verificar o EFEITO sobre o IFRS mandatório.

\subsection{Amostra}

A fim de testar a hipótese proposta neste trabalho, foram analisadas empresas brasileiras não financeiras de capital aberto listadas na B3, conforme sugere Silva (2013), pois as empresas financeiras e seguradoras prejudicam a análise da alavancagem. O período da amostra é o compreendido entre 2003 e 2014. Foi escolhido esse período de análise, visando adquirir informações robustas num período de 12 anos, assim como pela facilidade e disponibilidade de informações. Além disso, Horton, Serafeim e Serafeim (2013) afirmam que, ao analisar-se um período maior, tende-se a eliminar o efeito aprendizagem.

Para a seleção da amostra, foram consideradas as empresas com negociação de ações ativas na B3, com índice de liquidez maior que 0,001. Assim como sugere Silveira (2002; 2005) e Carvalho de Alencar e Lopes (2008), "companhias com liquidez muito baixa possuem uma probabilidade menor de ter suas cotações adequadas ao valor de mercado". Com isso, essa consequência poderia distorcer os resultados, porque a baixa negociação poderia gerar observações com outliers, prejudicar a amostra e, posteriormente, a análise.

Considerou-se, para a aferição da liquidez das empresas, o indicador técnico do sistema Economática ${ }^{\circledR}$, conforme trabalhos de Carvalho de Alencar e Lopes (2008) e Silveira (2002, 2005). Foi feito um corte dentro do período analisado neste trabalho, entre 2003 e 2014, excluindo-se os anos de 2008 e 2009, por se tratar do período de adoção voluntária, evitando-se, conforme Houqe e Easton (2013), a contaminação da amostra pelo período voluntário. Por isso, a amostra considerada para esse estudo foi de 72 empresas brasileiras. Os dados secundários foram obtidos do sistema Economáticaß e também no sítio eletrônico da B3.

\subsubsection{Robustez da Amostra}

Sabe-se que há uma preocupação para o tratamento de outliers nas amostras. Wooldridge (2010, p. 306) diz que as análises são influenciadas por outliers, a ponto de alterarem a significância do p-valor.

Seguindo o tratamento utilizado por Castro Junior e Yoshinaga (2012) para tratar outliers (observações extremas), foram utilizadas variáveis "winsorizadas", por substituírem os extremos por observações imediatamente anteriores. Deste modo, $2 \%$ das observações foram consideradas extremas, sendo $1 \%$ para variação acima e 1\% para variação abaixo. Esta técnica está em linha com o trabalho de Barnett e Lewis (1994). 


\subsection{Definição das Variáveis}

\subsubsection{Variáveis Dependentes}

Para testar a relação de criação de valor da firma, foram utilizadas duas variáveis, q de Tobin e Market-to-Book, conforme sugerido nos trabalhos de Kayo et al. (2006), de Teh et al. (2008) e de Motta, Oliveira, Cavazotte, Figueiredo e Klotzle (2013). É esperado que haja entre o IFRS mandatório e a criação de valor relação positiva e significante.

O a de Tobin, neste trabalho, foi calculado da seguinte forma: a razão entre a soma do passivo não circulante e o valor de mercado da Ação sobre o Ativo Total da empresa i no ano t. Representado no modelo por QTOBIN.

Market-to-Book: A razão entre valor de Mercado da ação e valor patrimonial. Representado no modelo por MTB.

\subsubsection{Variáveis de Interesse}

As variáveis de interesse adotadas estão em linha com Wooldridge (2010), já demonstradas aqui na equação 1. Logo, conforme equação 2 , as variáveis de interesse para esta pesquisa são TEMPO, TRATAMENTO e EFEITO, onde:

TEMPO; é a dummy que assume valor 1 para o período a partir de 2010. Caso contrário, assume zero(0).

TRATAMENTO; é a dummy que assume valor 1 para todas as empresas que adotaram IFRS no período mandatório e que não pertencem ao grupo de controle. Caso contrário, assume zero (0).

EFEITO i é a multiplicação da variável TEMPO e TRATAMENTO. A dummy assume valor 1 quando a observação pertencer ao período mandatório (TEMPO = "1") e ao grupo de empresas tratadas (TRATAMENTO = "1"). Caso contrário, assume zero (0). Em linhas gerais, obtém-se o EFEITO multiplicando a variável $\left(\right.$ TEMPO $_{i}$ * TRATAMENTOi). Esta variável isola o EFEITO do IFRS mandatório por controlar as características não observáveis. Portanto, é especificamente a variável de interesse a qual conseguirá medir a relação do IFRS mandatório com a criação de valor.

\subsubsection{Varióveis de Controle (VC)}

Ativo Total, representando o tamanho da firma; esse está calculado com - logaritmo neperiano do Ativo total e é representado no modelo por TAMANHO. Empresas maiores têm maior acesso ao capital, visto que pode ser facilmente mensurável por meio dos ativos da empresa. Com isso, é esperado que esta variável tenha relação positiva na criação de valor de mercado.

Alavancagem é a soma do passivo circulante com o passivo não circulante, dividido por Patrimônio Líquido. Representado no modelo por ALAVANCAGEM. Empresas mais endividadas incorrem em maiores custos, devido à percepção de risco dos credores e acionistas. É esperado que essa variável tenha relação negativa na criação de valor. 
Crescimento da Receita líquida operacional: logaritmo neperiano entre a variação anual da receita líquida operacional da empresa i entre os anos t sobre t-1, representado no modelo por CRESC RECEITA. Quanto maior for a variação positiva no crescimento anual da receita líquida operacional de um ano t por anot1, maior será o crescimento operacional da empresa naquele ano em que há maior variação anual positiva da receita líquida operacional. É esperado que esta variável tenha relação positiva com a criação de valor.

Dummies de Setor: representam todos os setores baseados nos setores da empresa Economáticaß. A dummy assume valor 1 para as empresas pertencentes ao grupo do setor; caso contrário, assume valor zero (0). Desta forma, a pesquisa busca controlar características comuns às empresas de um mesmo setor e que as distinguem dos demais. Espera-se que dummy de setor capture a criação de valor dos ativos intangíveis, visto que o setor pode gerar um benefício futuro não financeiro (Kayo et al., 2006).

Desta forma, para atender o objetivo de análise da relação do Efeito do IFRS na criação de valor, foram considerados mais especificamente os Modelo 1 e Modelo 2:

$$
\begin{aligned}
& \quad Q T O B I N=\beta_{0}+\beta_{1} \times \text { TEMPO }_{i, t}+\beta_{2} \times \text { TRATAMENTO }_{i, t}+\beta_{3} \times \text { EFEITO }_{i, t}+ \\
& \beta^{\prime} \times V C_{i, t}+\varepsilon_{i, t}
\end{aligned}
$$

Esse modelo tem, como variável dependente, q de Tobin, que neste trabalho foi calculado da seguinte forma: Passivo não Circulante somado ao Valor de Mercado da Ação; o resultado desta soma se divide pelo Ativo Total.

$$
\begin{aligned}
& M T B=\beta_{0}+\beta_{1} \times \text { TEMPO }_{i, t}+\beta_{2} \times \text { TRATAMENTO }_{i, t}+\beta_{3} \times \text { EFEITO }_{i, t}+ \\
& \beta^{\prime} \times V C_{i, t}+\varepsilon_{i, t}
\end{aligned}
$$

Esse modelo tem como variável dependente MTB (Market-to-Book), que é o valor de mercado da ação dividido pelo valor patrimonial.

$\beta_{1} ; \beta_{2} ; \beta_{3}$ e $\beta$ ' são os interceptos; Por VC, lê-se variáveis de controle e $\varepsilon$ equivale ao erro da equação. 


\begin{tabular}{|c|c|}
\hline Variáveis & Definição \\
\hline Q de Tobin (Qtobin) & $\begin{array}{l}\text { a razão entre a soma do passivo não } \\
\text { circulante e o valor de mercado da Ação } \\
\text { sobre o Ativo Total da empresa i no ano t. } \\
\text { Representado no modelo por Qtobin. }\end{array}$ \\
\hline Market-To-Book (Mtb) & $\begin{array}{l}\text { A razão entre valor de Mercado da ação } \\
\text { dividido pelo valor patrimonial. }\end{array}$ \\
\hline Tempo & $\begin{array}{l}\text { É a dummy que assume valor } 1 \text { para o } \\
\text { período a partir de } 2010 \text {. Caso contrário, } \\
\text { assume zero (0). }\end{array}$ \\
\hline Tratamento & $\begin{array}{l}\text { É a dummy que assume valor I para } \\
\text { todas as empresas que adotaram IFRS no } \\
\text { período mandatório e que não } \\
\text { pertencem ao grupo de controle. Caso } \\
\text { contrário, assume zero (0). }\end{array}$ \\
\hline Efeito & $\begin{array}{l}\text { É a multiplicação da variável TEMPO e } \\
\text { TRATAMENTO. A dummy assume valor } 1 \\
\text { quando a observação pertencer ao } \\
\text { período mandatório (TEMPO = "1") e ao } \\
\text { grupo de empresas tratadas } \\
\text { (TRATAMENTO = "1"). Caso contrário, } \\
\text { assume zero (0). Em linhas gerais, obtém- } \\
\text { se o EFEITO multiplicando a variável } \\
\text { (TEMPO * TRATAMENTO). }\end{array}$ \\
\hline Tamanho & $\begin{array}{l}\text { calculado com o logaritmo neperiano do } \\
\text { Ativo total é representado no modelo por } \\
\text { Tamanho }\end{array}$ \\
\hline Alavancagem & $\begin{array}{l}\text { É a soma do passivo circulante com o } \\
\text { passivo não circulante, dividido por } \\
\text { Patrimônio Líquido }\end{array}$ \\
\hline Cresc Receita & $\begin{array}{l}\text { Crescimento da Receita líquida } \\
\text { operacional: logaritmo neperiano entre a } \\
\text { variação anual da receita líquida } \\
\text { operacional da empresa i entre os anos † } \\
\text { sobre t-1, representado no modelo por } \\
\text { CRESC RECEITA }\end{array}$ \\
\hline Dummies de Setor & $\begin{array}{l}\text { representam todos os setores baseados } \\
\text { nos setores da empresa Economática®. A } \\
\text { dummy assume valor } 1 \text { para as empresas } \\
\text { pertencentes ao grupo do setor; caso } \\
\text { contrário, assume valor zero (0) }\end{array}$ \\
\hline
\end{tabular}

Figura 2 - Definição das variáveis

Fonte: Elaborado pelos autores.

\section{DISCUSSÃO}

\subsection{Estatística Descritiva e Análise da Matriz de Correlação}

A análise descritiva sugere que as empresas tratadas, tabela 1, demonstraram os primeiros benefícios, pelo menos com a variável dependente a de Tobin, criação de valor para as empresas após IFRS mandatório (Bushman \& Smith, 2001, 2003; Daske et al., 2008; FERREIRA et al., 2015). A variável MTB tem seu valor de média e mediana praticamente inalterado, com decréscimo 0,01. De forma geral e descritiva, essas alterações positivas detectadas na criação de 
valor ocorreram por terem gerado maior evidenciação e mensuração contábil financeira, e também pela maior capacidade de comparabilidade das empresas dos analistas de mercado (FERREIRA et al., 2015).

No ínterim, as empresas tratadas após adoção do IFRS aumentaram de tamanho, mantiveram o crescimento das receitas e aumentaram suas capacidades de alavancagem. Com isso, criaram valor positivo. $O$ q de Tobin apresentou melhora, indicando valores tanto na média quanto na mediana acima de 1. Essa informação é muito positiva, pois, segundo Famá e Barros (2000), isso é indicador para empresas que têm ótimo incentivo de crescimento significativo.

Tabela 1

Estatística Descritiva - Empresas de Tratamento

\begin{tabular}{l|c|c|c|c|c|c}
\hline & \multicolumn{3}{c|}{ Período: $2003-\mathbf{2 0 0 7}$} & \multicolumn{3}{c}{ Período: 2010 - 2014 } \\
\hline \multicolumn{1}{c|}{ Variável } & Média & Mediana & D.P & Média & Mediana & D.P \\
\hline TAMANHO & 15,02 & 14,76 & 1,87 & 15,70 & 15,30 & 1,65 \\
\hline CRESC RECEITA & 0,16 & 0,14 & 0,28 & 0,16 & 0,12 & 0,34 \\
\hline ALAVANCAGEM & 0,30 & 0,35 & 1,24 & 0,36 & 0,10 & 1,21 \\
\hline QTOBIN & $\mathbf{1 , 2 7}$ & $\mathbf{0 , 8 9}$ & $\mathbf{0 , 8 8}$ & $\mathbf{1 , 5 2}$ & $\mathbf{1 , 0 7}$ & $\mathbf{1 , 3 1}$ \\
\hline MTB & $\mathbf{3 , 0 1}$ & $\mathbf{2 , 0 0}$ & $\mathbf{3 , 5 1}$ & $\mathbf{3 , 0 0}$ & $\mathbf{1 , 7 0}$ & $\mathbf{4 , 1 3}$ \\
\hline
\end{tabular}

Fonte: Elaborada pelos autores.

Nota: Todas as variáveis - TAMANHO, ALAVANCAGEM, CRESC RECEITA, QTOBIN e MTB correspondem a valores/indicadores anuais. Quando não representarem indicadores, as variáveis extraídas são reais milhões, dados esses capturados da base de dados da Economática ${ }^{\circledR}$. A variável TAMANHO (Ativo Total) é apresentada em logaritmo neperiano. Período da análise entre 2003 - 2007 e 2010 - 2014. Empresas controladas são aquelas que adotaram padrão US GAAP anterior a 2008. Empresas tratadas são aquelas que adotaram IFRS no período mandatório, a partir de 2010.

Já a estatística descritiva das empresas controladas apresentou decréscimo da criação de valor tanto pelo q de Tobin quanto Market-to-Book. As empresas não apresentaram aumento do crescimento da receita, mas esse movimento negativo foi compensado pelo aumento na capacidade de alavancagem e aumento do tamanho das empresas. Segundo Famá e Barros (2008), o q de Tobin acima de 1 é incentivo positivo para se investir na empresa. Esse fato está demostrado, pelo menos, no valor médio apresentado pelas empresas controladas (vide tabela 2).

\section{Tabela 2}

Estatística Descritiva das Empresas Controladas

\begin{tabular}{l|c|c|c|c|c|c}
\hline & \multicolumn{3}{|c|}{ Período: 2003 - 2007 } & \multicolumn{3}{c}{ Período: 2010 - 2014 } \\
\hline \multicolumn{1}{c|}{ Variável } & Média & Mediana & D.P & Média & Mediana & D.P \\
\hline TAMANHO & 15,00 & 14,84 & 1,60 & 16,05 & 16,07 & 1,39 \\
\hline CRESC RECEITA & 0,23 & 0,14 & 0,31 & 0,13 & 0,10 & 0,23 \\
\hline ALAVANCAGEM & 0,61 & 0,41 & 0,99 & 0,65 & 0,52 & 0,93 \\
\hline QTOBIN & $\mathbf{1 , 3 9}$ & $\mathbf{1 , 1 2}$ & $\mathbf{1 , 0 1}$ & $\mathbf{1 , 2 5}$ & $\mathbf{0 , 9 5}$ & $\mathbf{0 , 8 8}$ \\
\hline MTB & $\mathbf{3 , 0 3}$ & $\mathbf{2 , 1 3}$ & $\mathbf{2 , 7 9}$ & $\mathbf{2 , 3 6}$ & $\mathbf{1 , 6 0}$ & $\mathbf{2 , 4 7}$ \\
\hline
\end{tabular}

Nota: Todas as variáveis - TAMANHO, ALAVANCAGEM, CRESC RECEITA, QTOBIN e MTB correspondem a valores/indicadores anuais. Quando não representarem indicadores, as variáveis extraídas são reais milhões, dados esses capturados da base de dados da Economática ${ }^{\circledR}$. A variável TAMANHO (Ativo Total) é apresentada em logaritmo neperiano. Período da análise entre 2003 - 2007 e 2010 - 2014. Empresas controladas são aquelas que adotaram padrão US GAAP anterior a 2008. Empresas tratadas são aquelas que adotaram IFRS no período mandatório, a partir de 2010. 
A análise da matriz de correlação verificou se as variáveis dependentes apresentaram correlação com o modelo proposto das variáveis dependentes. Além disso, é possível verificar se há indícios de autocorrelação e, caso alguma variável esteja explicando na mesma proporção, correlação 1 ou muito próxima de 1, é recomendado pela literatura que se exclua tal variável para não diminuir o poder explicativo, diminuindo, desse modo, a significância dos modelos analisados (Hair et al., 2005).

Na matriz de correlação, tabela 3, percebe-se que nenhuma variável independente apresenta correlação muito elevada, o que inviabilizaria estarem no modelo analisado (Hair et al., 2005). O q de Tobin apresentou correlação inversamente proporcional com o tamanho e alavancagem, e diretamente proporcional com o crescimento da receita. Praticamente a mesma relação foi observada na variável MTB, porém apresentou relação positiva com a alavancagem.

\section{Tabela 3}

Matriz de Correlação das Variáveis

\begin{tabular}{cccccr}
\hline TAMANHO & CRESC RECEITA & ALAV & QTOBIN & MTB & \\
\hline 1,00 & $-0,06$ & $-0,01$ & $-0,12$ & $-0,12$ & TAMANHO \\
& 1,00 & 0,03 & 0,07 & 0,04 & CRESC RECEITA \\
& 1,00 & $-0,12$ & 0,19 & ALAVANCAGEM \\
& & 1,00 & 0,75 & QTOBIN \\
& & & & 1,00 & MTB \\
\hline
\end{tabular}

Fonte: Elaborada pelos autores.

Nessa seção, foi possível analisar as estatísticas descritivas que possuem baixo a moderado poder explicativo, e forneceu indícios sobre a assertividade da hipótese a ser testada (Hair et al., 2005; Wooldridge, 2010). No entanto, essa estatística não possui alto poder de explicação e, portanto, fez-se necessário analisar de forma mais robusta essa relação entre criação de valor e IFRS por meio do método de diferença em diferenças. Esse método é capaz de isolar o efeito que se deseja capturar, por meio da comparação do grupo de tratamento com o grupo de controle; e, com isso, constatar se a adoção mandatória do IFRS (efeito capturado) influenciou positivamente na criação de valor das companhias. Ainda nessa seção, pôde-se analisar a matriz de correlação que, após análise, decidiu-se por manter as variáveis propostas nos modelos.

As seções seguintes irão aprofundar mais a análise, por meio do método de diferença em diferenças (diff-in-diff).

\subsection{Análise dos Resultados pelo Modelo de Diferença em Diferenças}

Esta seção procurou indicativos probabilísticos quanto à capacidade do IFRS mandatório ter relação com a criação de valor. Para avaliar esta relação, foram utilizadas as variáveis QTOBIN e MTB, respectivamente modelos 1 e 2. 
No que tange aos resultados apresentados pela variável de interesse explicativo EFEITO, que capturou, por meio do método com estimadores diferença em diferenças o efeito do IFRS no período mandatório, a fim de verificar se foi criado valor positivo, este resultado apresentou relação positiva e significante estatisticamente ao nível de $1 \%$ para a variável dependente QTOBIN, conforme Tabela 4. Logo, pôde-se aceitar a hipótese, pois se demonstrou que o IFRS mandatório impactou positivamente e de forma significante estatisticamente na criação de valor, mensurado aqui pela variável QTOBIN. O mesmo resultado foi encontrado para o modelo que utiliza estimadores $M Q O$, visto que apresentou variação positiva com significância estatística de 1\%, conforme Tabela 4.

Na pesquisa de Daske (2006), que investigou a partir de dados coletados em 26 países o impacto do IFRS na criação de valor, mais especificamente na variável q de Tobin, encontrou-se efeito positivo, porém não foi possível constatar a significância do achado, talvez por conta do efeito da curva de aprendizagem para o mercado e do tamanho da amostra (Ball, 2006; Ferreira et al., 2015). Ocorre que a Tabela 4, com resultados desta pesquisa, com janela de cinco anos antes e após o IFRS mandatório, eliminou esse problema da curva de aprendizagem, conforme sugestão de Houqe e Easton (2013), adotada neste artigo; e, dessa forma, demonstrou-se que o IFRS mandatório impactou positivamente a criação de valor. Esses resultados estão em linha com os estudos feitos no Brasil, nos artigos de Silva (2013) e Gasparini (2015), e na Europa, como em Li (2010).

As empresas que foram analisadas nesse artigo no grupo de tratamento apresentaram criação de valor. Essa relação está em linha com o que já era esperado por Bushman e Smith $(2001,2003)$. Tal pesquisa ocorreu antes da primeira adoção do IFRS por alguns países europeus no ano de 2005, pois assumiram que a maior qualidade dos demonstrativos financeiros contábeis tem relação positiva com o valor futuro da empresa. Tais constatações empíricas também são sustentadas pelos achados de Barth et al. (2008), que encontraram que normas internacionais de contabilidade estão associadas positivamente à maior qualidade dos demonstrativos financeiros, que ajudam as empresas e analistas de mercado de capitais a enxergarem qual o valor futuro dos projetos das empresas, sejam eles os relacionados aos tangíveis, sejam relativos aos intangíveis (Coombs; Bierly, 2006). Além dessas, houve também a pesquisa de Pae et al. (2006), que constataram relação positiva e significante do QTOBIN e IFRS num estudo feito com dados da UE.

Tais achados não indicam que as empresas criaram projetos novos após o IFRS mandatório, e que isso teria criado valor positivo para as empresas, mas sugere que os projetos das empresas estavam registrados com critérios conservadores. A consequência foi que as empresas passaram a apresentar criação de valor que possivelmente já estavam incorporadas, embora não explicitadas harmoniosamente nas antigas normas contábeis BR GAAP - isso foi o que se discutiu em Barth et al. (2008), em que a maior qualidade das demonstrações contábeis melhoram com as normas internacionais contábeis. Portanto, essa criação de valor foi capaz de ser capturada com as proxies de q de Tobin e Market-to-Book, conforme discutido nos trabalhos de Coombs e Bierly (2006), Pae et al. (2006) e Armstrong et al. (2010), pois têm o poder de identificar a reação do mercado a mudanças na qualidade dos demonstrativos financeiros contábeis. 
Já os setores que influenciaram positivamente o QTOBIN são: Alimentos e Bebidas; e Comércio, apresentando significância estatística de $10 \%$ e 5\%, respectivamente.

Como já dito, a criação de valor se dá pela somatória dos ativos tangíveis e intangíveis e, segundo Teh et al. (2008), uma forma com que as empresas criam benefícios intangíveis pode ser constatada por meio do setor de atuação delas.

Este artigo procurou medir o impacto dos vários setores na criação de valor das empresas, e foi constatado, conforme modelo 1, Tabela 4, pelo método diff-in-diff, que os setores de alimentos e bebidas e comércio capturaram valor positivo e significante estatisticamente, de acordo com o esperado do conceito de ativos intangíveis. Ainda através do método econométrico por MQO, Tabela 4, também apresentaram-se criação de valor e significância estatística para os setores de mineração, minerais não metálicos, petróleo e gás, têxtil e transportes e serviços.

O modelo 2, na Tabela 4, procurou confirmar se houve criação de valor, utilizando como variável dependente o Market-to-Book (MTB). Esta variável representa a percepção do mercado em relação ao valor patrimonial. A Tabela 4 mostrou que a regressão em painel com estimadores diff-in-diff, por meio da variável EFEITO, capturou que o IFRS mandatório tem relação positiva $(0,71)$ e significância estatística de 1\%. Sendo assim, pelo método diff-in-diff com dados em painel, foi isolado o efeito positivo na variável MTB. O Método econométrico de diff-in-diff aplicado apresentou-se eficiente em isolar o efeito esperado do IFRS mandatório com relação à criação de valor e significante estatisticamente a $1 \%$, por meio da variável Market-to-Book. E a análise com os dados em cross section pelo método do MQO também resultou na relação positiva e significância estatística ao nível de $5 \%$. 
Tabela 4

Regressão Efeito aleatórios (E.A) e Mínimo quadrado ordinário (M.Q.O)

\begin{tabular}{|c|c|c|c|c|c|c|c|c|c|c|}
\hline & \multicolumn{6}{|c|}{ Modelo $1-Q$ de Tobin } & \multicolumn{4}{|c|}{ Modelo 2 - MTB } \\
\hline \multirow{2}{*}{$\begin{array}{l}\text { MODELO: } \\
\text { Variáveis }\end{array}$} & \multicolumn{3}{|c|}{ Efeito Aleatório } & \multicolumn{3}{|c|}{ MQO } & \multicolumn{2}{|c|}{ Efeito Aleatório } & \multicolumn{2}{|l|}{ MQO } \\
\hline & \multicolumn{2}{|c|}{ QTOBIN } & \multirow{2}{*}{$\frac{d p}{0.76}$} & \multicolumn{2}{|c|}{ QTOBIN } & \multirow{2}{*}{$\frac{d p}{0,40}$} & MTB & $d p$ & MTB & \multirow{2}{*}{$\frac{d p}{1,16}$} \\
\hline Constante & 1,97 & $* * *$ & & 2,42 & $* * *$ & & 1,38 & 2,09 & $3,43^{* * *}$ & \\
\hline TAMANHO & $-0,05$ & & 0,05 & $-0,08$ & $* * *$ & 0,03 & 0,06 & 0,13 & $-0,09$ & 0,08 \\
\hline CRESC RECEITA & 0,21 & $* *$ & 0,09 & 0,16 & & 0,13 & 0,32 & 0,22 & 0,15 & 0,39 \\
\hline ALAVANCAGEM & $-0,18$ & $* * * *$ & 0,03 & $-0,11$ & $* * *$ & 0,03 & $0,34 * * *$ & 0,07 & $0,59 * * *$ & 0,10 \\
\hline TEMPO & $-0,10$ & & 0,08 & $-0,08$ & & 0,09 & $-0,77^{* * *}$ & 0,19 & $-0,70^{* * *}$ & 0,25 \\
\hline TRATAMENTO & $-0,27$ & & 0,23 & $-0,29$ & $* *$ & 0,11 & $-0,14$ & 0,71 & $-0,17$ & 0,33 \\
\hline EFEITO & 0,41 & $* * *$ & 0,11 & 0,45 & *** & 0,15 & $0,71 \quad * * *$ & 0,26 & $0,88^{* *}$ & 0,44 \\
\hline ALIMENTOS E & 0,94 & * & 0,56 & 1,05 & $* * *$ & 0,21 & 1,50 & 1,72 & $1,88^{* * *}$ & 0,60 \\
\hline COMÉRC & 1,19 & $* *$ & 0,47 & 1,15 & $* * *$ & 0,17 & $5,66 \quad * * *$ & 1,45 & $5,67 \quad * * *$ & 0,50 \\
\hline CONSTRUÇÃO & $-0,18$ & & 0,55 & $-0,14$ & & 0,2 & $-0,52$ & 1,72 & $-0,35$ & 0,59 \\
\hline ENERGIA & 0,03 & & 0,38 & 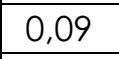 & & 0,14 & $-0,33$ &, 18 & $-0,09$ & 0,41 \\
\hline $\begin{array}{l}\text { MÁQUINAS } \\
\text { INDUSTRIAIS } \\
\end{array}$ & 0,29 & & 0,64 & 0,32 & & 0,23 & 0,70 & 1,99 & 0,83 & 0,66 \\
\hline MINERAÇÃO & 0 & & 8 & 78 & $* *$ & 33 & 0,42 & 70 & 4 & 0,93 \\
\hline $\begin{array}{l}\text { MINERAIS NÃO } \\
\text { METÁLICOS }\end{array}$ & $-0,19$ & & 0,86 & $-0,18$ & & 0,31 & $-0,28$ & 2,66 & $-0,31$ & 0,89 \\
\hline OUTROS & 0,35 & & 0,40 & 0,44 & *** & 0,15 & 1,08 & 1,25 & $1,46 \quad * * *$ & 0,44 \\
\hline PAPEL \& CELULOSE & $-0,09$ & & 0,65 & $-0,02$ & & 0,24 & $-1,05$ & 2,01 & $-0,73$ & 0,68 \\
\hline PETRÓLEO e GÁS & 0,32 & & 0,56 & 0,38 & $*$ & 0,21 & $-0,42$ & 1,73 & $-0,19$ & 0,59 \\
\hline QUÍMICA & 0,06 & & 0,56 & 0,12 & & 0,21 & $\mid-0,61$ & 1,72 & $-0,31$ & 0,61 \\
\hline $\begin{array}{l}\text { SIDERÚRGIA e } \\
\text { METALÚRGIA }\end{array}$ & $-0,09$ & & 0,41 & $-0,06$ & & 0,15 & $-0,20$ & 1,28 & $-0,16$ & 0,43 \\
\hline TELECOMUNICA & $-0,10$ & & 0,57 & 0,01 & & 0,21 & $-0,72$ & 1,74 & $-0,24$ & 0,60 \\
\hline TEXTIL & 0,52 & & 0,47 & 0,54 & $* * *$ & 0,17 & 0,72 & 1,46 & 0,76 & 0,49 \\
\hline $\begin{array}{l}\text { TRANSPORTES } \\
\text { SERVIÇOS }\end{array}$ & 0,63 & & 0,51 & 0,66 & $* * *$ & 0,19 & 1,31 & 1,57 & $1,63^{* * *}$ & 0,57 \\
\hline N. Obs. & & 682 & & & 682 & & & 665 & & 665 \\
\hline
\end{tabular}

Fonte: Elaborada pelos autores.

*; ** e *** denotam significância aos níveis de 10\%; $5 \%$ e 1\%, respectivamente.

Nota: Modelo 1: variável dependente QTOBIN e Modelo 2: variável dependente MTB.

Modelo 1 Analisa com estimadores de diferenças em diferenças com dados organizados em painel efeito aleatório e Modelo 2 analisa com MQO com dados em cross section. Todas as variáveis - TAMANHO, ALAVANCAGEM, CRESC RECEITA, QTOBIN e MTB (Market-to-Book) correspondem a valores/indicadores anuais. As variáveis extraídas estão com valores em reais milhões, extraídos a partir da base de dados da empresa Economática®. Períodos analisados: 2003 - 2007 e 2010 - 2014. "Grupo de empresas controladas" se refere às que adotaram padrão US GAAP anterior a 2008. "Grupo de empresas Tratadas" se refere às empresas que adotaram IFRS no período mandatório, a partir de 2010.

Estes resultados estão em linha com a pesquisa de Ferreira et al. (2015), que encontraram efeito positivo e com significância estatística de 5\%. Os mesmos autores sugeriram que novas pesquisas testassem novamente esta relação, porém em métodos com estimadores diff-in-diff, como foi apresentado neste artigo. Em comparação com o resultado encontrado em Ferreira et al. (2015), apurou-se que houve melhor significância estatística, ou seja, de 1\%, superior aos 
5\% capturados por Ferreira et al. (2015). O efeito encontrado por Ferreira et al. (2015) está em linha ao que foi capturado na Tabela 4, utilizando o MQO, em que o efeito é demonstrado positivo com significância estatística de 5\%. E, utilizando dados em painel com efeito aleatório com estimadores diff-in-diff, obtiveram-se resultados com maior significância estatística ao nível de $1 \%$ e maior robustez; além disso, os dados desta pesquisa foram "winsorizadas", contribuindo assim para eliminar as observações extremas e aumentar robustez dos resultados.

Com a finalidade de verificar a robustez dos resultados descritos, este artigo utilizou o teste do modelo diff-in-diff, com dados organizados em painel, com a variável dependente BETA.

O objetivo de se mensurar o risco da empresa é estabelecido pelos seguintes motivos: conforme artigo de Aboody e Lev (1998), o risco da empresa, medido pelo Beta, tem relação diretamente proporcional com ativos intangíveis. Essa relação é sensata, visto que os ativos intangíveis contribuem para criação de valor, fazendo jus à relação esperada de que menor risco deve apresentar maior valor de empresa (Kayo et al., 2006). Essa relação de risco antes e após o IFRS mandatório faz sentido ser testada como robustez, pois o risco é parte do componente da criação de valor.

Medir o risco (Beta) é uma forma mais sutil de se verificar a criação de valor, porque, quanto menor o risco, maior o valor presente líquido atribuído à empresa. Nesse sentido, a relação entre risco (Beta) e IFRS mandatório é menos sensível a apresentar relação significante, visto que o risco é parte do componente da criação de valor. Por isso, este teste se justifica como robustez dos resultados já encontrados.

O Beta (risco da empresa) já foi testado como variável dependente em outros artigos - por exemplo, Castro Junior et al. (2011) e Carvalho de Alencar (2005). Espera-se, então, que o Beta apresente sinal inverso ao apresentado nas variáveis de criação de valor. O Beta do ativo, neste artigo, foi calculado e extraído da base de dados Economática. O Beta do ativo equivale à covariância dos retornos diários da ação com janelas de dois anos com retorno de mercado sobre a variância do retorno da carteira de mercado. A carteira de mercado adotada como benchmark foi o retorno da carteira Ibovespa, conforme Castro et al. (2011) e Carvalho de Alencar (2005). 
Tabela 5

Regressão Efeito Aleatório (GLS) - Beta

\begin{tabular}{l|cl|c}
\multicolumn{1}{c|}{ MODELO: } & \multicolumn{3}{c}{ Efeito Aleatório } \\
Variáveis & \multicolumn{2}{|c}{ BETA } & dp \\
\hline Constante & $-\mathbf{1 , 2 4 7 4}$ & $* * *$ & 0,18 \\
\hline TAMANHO & $\mathbf{0 , 1 1 6 1}$ & $* * *$ & 0,01 \\
\hline CRESC RECEITA & $-\mathbf{0 , 0 7 4 7}$ & ${ }^{* * *}$ & 0,03 \\
\hline ALAVANCAGEM & $\mathbf{0 , 0 1 7 7}$ & $* *$ & 0,01 \\
\hline TEMPO & $-0,0164$ & & 0,02 \\
\hline TRATAMENTO & 0,0255 & 0,05 \\
\hline EFEITO & $-\mathbf{0 , 0 5 1 3}$ & $*$ & 0,03 \\
\hline N. Obs. & \multicolumn{3}{c}{647} \\
\hline
\end{tabular}

Fonte: Elaborada pelos autores.

Nota: variável dependente BETA. Modelo de análise diferenças em diferenças com dados organizados em painel efeito aleatório.

*; ** $e^{* * *}$ denotam significância aos níveis de $10 \% ; 5 \%$ e $1 \%$, respectivamente.

Este modelo analisa com estimadores de diferenças em diferenças com dados organizados em painel efeito aleatório. Todas as variáveis - TAMANHO, ALAVANCAGEM, CRESC RECEITA, correspondem a valores/indicadores anuais. As variáveis extraídas estão com valores em reais milhões, extraídos a partir da base de dados da empresa Economática®. Períodos analisados: 2003 - 2007 e 2010 - 2014. "Grupo de empresas controladas" se refere às que adotaram padrão US GAAP anterior a 2008. "Grupo de empresas Tratadas" se refere às empresas que adotaram IFRS no período mandatório, a partir de 2010.

Logo, para a análise da relação entre risco da empresa (Beta) e IFRS mandatório, no que tange aos resultados apresentados na tabela 5, a variável de interesse EFEITO, que captura por meio do método de diferença em diferenças (diff-in-diff), o efeito do IFRS para empresas no período mandatório apresentou relação negativa com significância estatística a 10\%, indicando que o IFRS mandatório diminuiu, em média, o risco das empresas, mensurado aqui pelo Beta do ativo.

Portanto, esse resultado está em linha com os resultados encontrados em Silva (2013) e Gasparini (2015), que pesquisaram a relação entre o custo de capital próprio e o IFRS mandatório. Também está em conformidade com o predito por Bushman e Smith (2001, 2003), Bartov et al. (2005), Barth et al. (2008) e Soderstrom e Sun (2007), em que se constata que os demonstrativos financeiros de qualidade, neste estudo capturado pelo efeito do IFRS mandatório, proporcionam mitigar a assimetria de informação, a ponto de impactar negativamente o risco da empresa que, por sua vez, impacta positivamente na criação de valor. Isso foi esperado por Aboody e Lev (1998), Kayo et al. (2006) e Pae et al. (2006).

\section{CONCLUSÕES}

O objetivo geral deste trabalho foi verificar a relação existente entre adoção mandatória do IFRS e criação de valor em empresas listadas na B3, no período de 2003 a 2014.

Foi verificado que o IFRS mandatório tem relação positiva com a criação de valor das empresas, com significância estatística. Para as variáveis q de Tobin (QTOBIN) e Market-to-Book (MTB), o impacto foi positivo, com significância estatística ao nível de $1 \%$. Esses resultados corroboram com a pesquisa de Daske 
(2006) e Pae et al. (2006). Uma outra evidência que se pôde tirar dos resultados foi: considerando que o Brasil é posto como um país de fraca proteção legal (LA PORTA, 1998), esse baixo poder de enforcement não impediu o país de colher benefícios do IFRS. Logo, faz-se importante comparar a contribuição deste estudo com a pesquisa de Houqe e Easton (2013), pois estes autores descobriram que, mesmo em países de baixo enforcement, o IFRS consegue promover benefícios para as empresas. Isso traduz o que Bushman e Smith $(2001,2003)$ chamam de melhor desempenho econômico a partir da alta qualidade das informações contábeis financeiras.

Portanto, O IFRS mandatório apresentou relação positiva e significante estatisticamente com a criação de valor e mostrou que o aumento da qualidade nos demonstrativos financeiros reduz a assimetria de informação e, consequentemente, aumentou o incentivo de disclosure nas firmas. Cabe adicionar que os autores Silva (2013) e Ferreira et al. (2015) entenderam que esses benefícios econômicos, a partir das normas IFRS, ocorreram nas rubricas contábeis de pagamentos baseados em ações, teste de impairment, ativos não correntes mantidos para venda e operações descontinuadas, registro de propriedade para investimento, dividendo adicional proposto no patrimônio líquido, reconhecimento dos contratos de concessão em ativo financeiro ou intangível, a conta ajuste de avaliação patrimonial destinada ao registro de variação de ativos e passivos avaliadas a valor justo, entre outros (Silva, 2013; Ferreira et al., 2015).

Como sugestão para novas pesquisas, outros autores poderiam testar outras variáveis bid-ask spread, a fim de procurar entender se a volatilidade do mercado acionário brasileiro reagiu favoravelmente após a adoção do IFRS.

Este artigo contribui para a literatura nacional e internacional, pela estratégia empírica adotada em dados em painel com estimadores diff-in-diff, com perspectivas de reduzir o viés da amostra e contornar a efeitos de variáveis endógenas. Também traz colaborações para elaboradores de políticas públicas do setor financeiro brasileiro, no que tange à adoção e efeitos positivos do IFRS. Para as empresas privadas, a incorporação do IFRS impacta positivamente na criação de valor e possibilita melhorar a sua performance com relação à competitividade, uma vez que possuem um padrão similar de comparabilidade das demonstrações financeiras.

Apesar das limitações com respeito ao tamanho da amostra por conta do tamanho do mercado brasileiro não ser muito desenvolvido e com muitas empresas, assim como mercado americano, estas não invalidam os resultados deste artigo, uma vez que os resultados são consistentes com as evidências internacionais e nacionais, contribuindo com algumas lacunas preenchidas para criação de valor, a partir da adoção do IFRS mandatório.

\section{REFERÊNCIAS}

Aboody, D.; \& Lev, B. (1998). The value relevance of intangibles: the case of software capitalization. Journal of Accounting Research, 36, 161-191. 
Armstrong, C., Barth, M. E., Jagolinzer, A. D., \& Riedl, E. (2010). Market reaction to the adoption of IFRS in Europe. The accounting review, 85 (1), 31-61.

Balakrishnan, K.; Li, X.; \& Yang, H. (2012). Mandatory financial reporting and voluntary disclosure: evidence from mandatory IFRS adoption. Disponível em: <http://ink.library.smu.edu.sg/soa_research/1 163/ >. Acesso em: 09 maio 2016.

Ball, R. (2006). International Financial Reporting Standards (IFRS): pros and cons for investors. Accounting and business research (Wolters Kluwer UK), 36 (1), 5-27. Disponível em: < doi/abs/10.1080/00014788.2006.9730040 >. Acesso em: 22 abr. 2015.

Barnett, V., \& Lewis, T. (1994). Outliers in statistical data. 3 ed. Chichester: Wiley.

Barth, M. E., Landsman, W. R., \& Lang, M. H. (2008). International accounting standards and accounting quality. Journal of accounting research, 46(3), 467498.

Bartov, E., Goldberg, S. R.; \& Kim, M. (2005). Comparative value relevance among German, US, and international accounting standards: A German stock market perspective. Journal of Accounting, Auditing \& Finance, 20 (2), 95-119.

Bushman, R. M., \& Smith, A. J. (2001). Financial accounting information and corporate governance. Journal of accounting and Economics, 32 (1), 237-333. Disponível em: < http://dx.doi.org/10.1016/S0165-4101(01)00027-1 >. Acesso em: 09 maio 2016.

Bushman, R. M., \& Smith, A. J. (2003). Transparency, financial accounting information, and corporate governance. Economic Policy Review, 9 (1). Disponível em: < http://ssrn.com/abstract=795547 >. Acesso em: 09 maio 2016.

Carvalho de Alencar, R. (2005). Custo do capital próprio e nível de disclosure nas empresas brasileiras. BBR-Brazilian Business Review, 2 (1), 1-12. Disponível em: < http://www.redalyc.org/articulo.oa?id=123016184001 >. Acesso em: 21 nov. 2015.

Carvalho de Alencar, R.; \& Lopes, A. B. (2008). Disclosure and cost of equity capital in emerging markets: the Brazilian case. In: VIII Encontro Brasileiro de Finanças. Disponível em: http://www.fucape.br/_public/producao_cientifica/2/Roberta.pdf > Acesso em: 13 ago. 2016.

Carvalho, E. M. (2014). Consequências econômicas da adoção compulsória das Normas Internacionais de Contabilidade (IFRS) no custo de capital próprio das empresas brasileiras listadas na BM\&BOVESPA. 147 f. Dissertação (Doutorado em Administração) - Universidade Federal do Rio Grande do Sul, Porto Alegre. Disponível em: < http://hdl.handle.net/10183/107268 >. Acesso em: 12 ago. 2016. 
Castro Junior, F. H. F, \& Yoshinaga, C. E. (2012). Coassimetria, cocurtose e as taxas de retorno das ações: uma análise com dados em painel. Revista de Administração Mackenzie, 13 (1), 110. Disponível em: < http://search.proquest.com/openview/cb lfc0bf6bc5196cfefb 1 fd98185b293/ 1 ?.pq-origsite=gscholar $>$. Acesso em: 10 maio 2016.

Castro Junior, F. H. F.; Conceição, P. M.; \& Santos, D. A. (2011). A relação entre o nível voluntário de transparência e o custo de capital próprio das empresas brasileiras não-financeiras. Revista Eletrônica de Administração, Porto Alegre: Ed. 70, 17 (3), 617-635, set./dez. Disponível em: < http://www.seer.ufrgs.br/read/article/download/38470/24722 >. Acesso em: 10 maio 2016.

Catty, J. P. (2013). IFRS: guia de aplicação do valor justo. Porto Alegre: Bookman Editora.

Coombs, J. E., Bierly III, \& Paul E. (2006). Measuring technological capability and performance. R\&D Management, 36 (4), 421-438.

Copeland, T. E., Koller, T., \& Murrin, J. (2002). Avaliação de empresas: valuation: calculando e gerenciando o valor das empresas. 3. ed. São Paulo: Makron Books.

CPC - Comitê de Pronunciamentos Contábeis. Pronunciamento Técnico CPC 04: Ativo Intangível. Disponível em: <http://www.cpc.org.br/pdf/CPC04_R1. pdf.>. Acesso em: 12 fev. 2020.

Daske, H. (2006). Economic benefits of adopting IFRS or US-GAAP-have the expected cost of equity capital really decreased? Journal of Business Finance \& Accounting, 33 (3-4), 329-373. Disponível em: $<$ http://search.ebscohost.com/login.aspx? direct=true\&db=buh\&AN=2087051 2\&lang=pt-br\&site=ehost-live $>$. Acesso em: 12 ago. 2016.

Daske, H., Hail, L., Leuz, C., \& Verdi, R. S. (2008). Mandatory IFRS reporting around the world: early evidence on the economic consequences. Journal of accounting research, 46 (5), 1085-1142. Disponível em: <doi/10.1111/j.1475679X.2008.00306.x >. Acesso em: 22 abr. 2016.

Famá, R., \& Barros, L. A. B. C. (2000). Q de Tobin e seu uso em finanças: aspectos metodológicos e conceituais. Caderno de Pesquisas em Administração, 7 (4), 27-43.

Ferreira, M. A., Flores, E., \& Martins, C. C. (2015). Análise do impacto do IFRS em indicadores financeiros em empresas brasileiras (Analysis of the Impact of IFRS Adoption on Financial Variables for Brazilian Companies). Available at SSRN. Disponível em: <http://dx.doi.org/10.2139/ssrn.2591536 > . Acesso em 10 maio 2016.

Gasparini, V. M. R. (2015). A adoção completa do IFRS e seus impactos no custo de capital próprio, calculados a partir de modelos de custo implícito de 
capital. 108f. Dissertação (Mestrado em Ciências Contábeis) - Universidade de São Paulo, Ribeirão Preto. Disponível em: < http://www.teses.usp.br/teses/disponiveis/96/96133/tde-21072015102627/en.php >. Acesso em: 10 maio 2016.

Gu, F., \& Li, J. Q. (2007). The credibility of voluntary disclosure and insider stock transactions. Journal of Accounting Research, 45 (4), 771-810. Disponível em: < http://search.ebscohost.com/login.aspx? direct=true \&db=buh\&AN=25736998 \&lang=pt-br\&site=ehost-live >. Acesso em 24 abr. 2016.

Hair, J. J., Babin, B., Money, A. H., \& Samouel, P. (2005). Fundamentos de métodos de pesquisa em administração. Porto Alegre: Bookman Companhia.

Horton, J., Serafeim, G., \& Serafeim, I. (2013). Does mandatory IFRS adoption improve the information environment? Contemporary Accounting Research, $30 \quad(1), \quad 388-423 . \quad$ Disponível em: < http://search.ebscohost.com/login. aspx? direct=true \& db=buh\&AN=86170288 \&lang=pt-br\&site=ehost-live $>$. Acesso em: 10 maio 2016.

Houqe, N., \& Easton, S. (2013). Does mandatory IFRS adoption improve information quality in low investor protection countries? Evidence from France, Sweden and Switzerland. Journal of International Accounting, Auditing \& Taxation (Forthcoming). Disponível em: < http://ssrn.com/abstract=2224278 >. Acesso em: 21 nov. 2015.

Kayo, E. K., Kimura, H., Martin, D. M. L., \& Nakamura, W. T. (2006) Ativos intangíveis, ciclo de vida e criação de valor. Revista de Administração Contemporânea, 10 (3), 73-90. Disponível em: <http://dx.doi.org/10.1590/S141565552006000300005 >. Acesso em: 14 jun. 2016.

La Porta, R., Silanes, F. L., Shleifer, A., \& Vishny, R. W. (1998). Law and finance. Journal of Political Economy, 106, p. 1113-1155. Disponível em: <https://works.bepress.com/florencio_lopez_de_silanes/18/ >. Acesso em: 19 abr. 2016.

Leland, H.; \& Pyle, D. H. (1977). Informational asymmetries, financial structure, and financial intermediation. Journal of Finance, 32 (2), 371-387, May. Disponível em:

http://search.ebscohost.com/login.aspx? direct=true \&db=buh\&AN=4657499\& lang=pt-br\&site=ehost-live >. Acesso em: 25 abr. 2016.

Li, S. (2010). Does mandatory adoption of international financial reporting standards in the European Union reduce the cost of equity capital?. The Accounting Review, 85 (2), 607-636. Disponível em: < http://dx.doi.org/10.2308/accr.2010.85.2.607 >. Acesso em: 25 abr. 2016.

Lima, G. A. S. F. (2009). Nível de evidenciação × custo da dívida das empresas brasileiras 1. Revista Contabilidade \& Finanças, 20 (49), 95-108. Disponível em: < http://www.revistas.usp.br/rcf/article/view/34284/37016 >. Acesso em: 21 nov. 2015. 
Martins, G. A. (2000). Manual para elaboração de monografias e dissertações. 2. ed. São Paulo: Atlas.

Megna, P., \& Klock, M. (1993). The impact of intangible capital on Tobin's $q$ in the semiconductor industry. The American Economic Review, 83 (2), 265-269.

Motta, L. F. J., Oliveira, P. V. C., Cavazotte, F. S. C. N., Figueiredo, A. C., \& Klotzle, M. C. (2013). Criação de valor em fusões e aquisições brasileiras. Revista de Administração FACES Journal, 12 (4). Disponível em: <http://fumec.br/revistas/facesp/article/view/1827/1342 >. Acesso em: 15 ago. 2016.

Pae, J., Thornton, D. B., \& Welker, M. (2006). The reduction of firms' ownership induced agency costs following financial reporting reform in the European Union. Available at SSRN 873607

Perez, M. M.; \& Famá, R. (2015). Características estratégicas dos ativos intangíveis e o desempenho econômico da empresa. Unisanta Law and Social Science, 4 (2), 107-123. Disponível em: < http://ojs.unisanta.br/index.php/Iss/article/view/393 >. Acesso em: 13 ago. 2016.

Rezende, C. V., Almeida, N. S., \& Lemes, S. (2015). Impacto das IFRS na assimetria de informação evidenciada no mercado de capitais brasileiro. Revista de Contabilidade e Organizações, v. 9, n. 24, p. 18-30. Disponível em: < http://dx.doi.org/10.11606/rco.v9i24.55524 >. Acesso em: 10 maio 2015.

Seth, A. (1990). Value creation in acquisitions: A re-examination of performance issues, 11 (2), 99-115, 1990.

Silva, R. L. M. (2013). Adoção completa das IFRS no Brasil: qualidade das demonstrações contábeis e o custo de capital próprio. 217 f. Tese (Doutorado em Ciências Contábeis) - Faculdade de Economia, Administração e Contabilidade, Universidade de São Paulo, São Paulo, 2013. Disponível em: < http://www.teses.usp.br/teses/disponiveis/12/12136/tde-03062013-

162758/en.php >. Acesso em: 10 maio 2016.

Silveira, A. D. M. (2002). Governança corporativa, desempenho e valor da empresa no Brasil. São Paulo. 152 p. Dissertação (Mestrado em Administração) - Faculdade de Economia, Administração e Contabilidade, Universidade de São Paulo. Disponível em: < http://www.teses.usp.br/teses/disponiveis/12/12139/tde-04122002102056/en.php >. Acesso em: 11 maio 2016.

Silveira, A. D. M. (2005). Governança corporativa: desempenho e valor da empresa no Brasil. São Paulo: Saint Paul Editora.

Soderstrom, N. S., \& Sun, K. J. (2007). IFRS adoption and accounting quality: a review. European accounting review, 16, (4), 675-702. 
Teh, C. C., Kayo, E. K.; \& Kimura, H. (2008). Marcas, patentes e criação de valor. Revista de Administração Mackenzie, 9 (1). Disponível em: <http://editorarevistas.mackenzie.br/index.php/RAM/article/view/154/154 >. Acesso em: 14 jun. 2016.

Verrecchia, R. E. (2001) Essays on disclosure. Journal of accounting and economics, 32 (1), 97-180. Disponível em < http://dx.doi.org/10.1016/S0165$4101(01) 00025-8>$. Acesso em 25 abr. 2016.

Wooldridge, J. M. (2010). Introdução à econometria: uma abordagem moderna. São Paulo: Cengage Learning.

Agradecimento:

Agradecemos o apoio da Coordenação de Aperfeiçoamento de Pessoal de Nível Superior - Brasil (CAPES) - Código de Financiamento 001. 